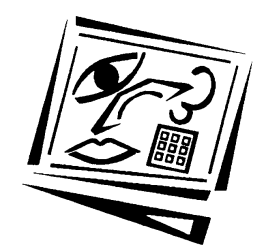

\title{
Patterns of engagement in authentic online learning environments
}

\author{
Jan Herrington, Ron Oliver \\ Edith Cowan University \\ Thomas C. Reeves \\ The University of Georgia, USA
}

\begin{abstract}
The use of authentic activities within online learning environments has been shown to have many benefits for learners in online units and courses. There has been renewed interest in the role of student activities within course units, as constructivist philosophy and advances in technology impact on educational design and practice. Courses based on these principles have been used successfully across a wide variety of discipline areas. In spite of the growing evidence of the success of authentic learning environments, they are not without their problems. In this paper we discuss patterns of engagement that have emerged from our own research on authentic learning tasks, in particular, the initial reluctance to willingly immerse in learning scenarios that some students experience, and the need for the suspension of disbelief before engaging in the task. The paper proposes ten characteristics of authentic activities, based on educational theory and research, which have been used as criteria for the selection of existing online units or courses for in depth investigation. The paper includes a short review of the literature, a description of the research and some preliminary findings and identification of issues related to the necessity for students to willingly suspend disbelief in order to fully engage in learning scenarios based on authentic tasks.
\end{abstract}

\section{Authentic activities in learning environments}

The use of authentic activities within online learning environments has been shown to have many benefits for learners in online units and courses. Instead of providing academic, decontextualised exercises that can be used primarily to practice a skill, there are many instances of courses where authentic tasks create the core of the online learning environment, and the completion of the tasks effectively comprises the entire student commitment for the course. Many courses have been based on complex and sustained scenarios and cases, where students become immersed in 
problem solving within realistic situations resembling the contexts where the knowledge they are learning can be realistically applied.

Authentic activities have been used successfully across a wide variety of discipline areas. For example, in a course entitled Physical activity fitness and health, students use a virtual laboratory to carry out fitness testing in areas such as muscular strength, aerobic power, lung function and flexibility in much the same manner that this procedure would be conducted with a real person (Rice, Owies, Campbell, Snow, Owen, \& Holt, 1999). The benefits to students of the design and construction of a Formula SAE racecar as part of mechanical and mechatronics engineering curriculum have been described by Bullen and Karri (2002), while Hunt, Kershaw and Seddon (2002) described a project where transition from school to university was approached with students' exploring the university campus in order to create video clips on the nature of university life, rather than the more traditional orientation activities. Marshall, Northcote and Lenoy (2001) have used authentic activities in their design of a course teaching mathematics to Indigenous adults. Bennett, Harper and Hedberg (2001) used case studies of the development of multimedia products as models for students of Interactive Multimedia Design to investigate, prior to their own development of multimedia products for real clients. An architecture learning environment has been developed (Challis, 2002) where students are required to compose a piece of music, and then design a scale model of a music room for the performance of the piece, described by the teacher as 'a means of allowing [the] design concept to transcend from the idea to the realisable' (p.107).

In spite of the growing evidence of the success of these authentic learning environments, they are not without their problems. In this paper we will discuss a problem that has emerged from our own research on authentic learning environments, namely, the initial reluctance to willingly immerse in learning scenarios that some students experience, and the need for the suspension of disbelief before engaging in the task.

\section{Authenticity in learning environments}

Some argue that it is impossible to design truly 'authentic' learning experiences. Petraglia (1998a, 1998b) argued that authenticity can be neither 'predetermined nor preordained', and such attempts often result in little more than 'preauthentication', that is, 'the attempt to make learning materials and environments correspond to the real world prior to the learner's interaction with them' (p.53). He gave the example of a task of balancing a checkbook, a task which may be authentic for a 21 year old, but hardly for a five year old. Even amongst the older age group, many factors contribute to whether they would find the task authentic-some 
would find 'any given lesson in personal finance irrelevant, inaccurate, or otherwise inappropriate' (p. 59). In supporting this view, Barab, Squire and Dueber (2000) argued that authenticity occurs 'not in the learner, the task, or the environment, but in the dynamic interactions among these various components ... authenticity is manifest in the flow itself, and is not an objective feature of any one component in isolation' (p. 38).

Petraglia (1998a) contended that learners need to be persuaded that they are participating in an authentic learning environment. This theme is also adopted by Kantor, Waddington and Osgood (2000) who, when referring to the kinds of goal based scenarios they design for Anderson Consulting, argued that:

No matter how realistic the case ... nor how authentic the conditions and tools ... [it] is not the same as a work environment. It is a simulation of a client engagement in which the participants tacitly agree to go along with an interpretation of job reality which we have crafted. (pp. 211-212)

There is increasing evidence that in order to fully engage with an authentic task or problem based scenario, students need to engage with a process that is familiar to moviegoers throughout the world - the suspension of disbelief. For example, consider the suspension of disbelief that audiences must undergo to enable them to become engaged with movies such as Star Wars, Mad Max, The Matrix, The Truman Show, and Back to the Future. Audiences need to accept the worlds that have been created, no matter how unlikely. Once the initial suspension of disbelief has occurred, it is only inconsistencies within the parameters of the plot itself that cause dissonance in the viewer. In other words, once the viewer has accepted the fundamental basis for the simulated world in which he or she is immersed, engagement with the story and message of the film is entirely feasible.

In scenario based learning environments, where conditions, characters, circumstances and parameters are drawn to simulate a real life context for learning, a similar suspension of disbelief is required. For some students, there appears to be some misapprehension about the approach, because it is so different from the more academic approaches with which they are familiar. Many students initially perceive authentic environments to be non-academic, non-rigorous, time wasting and unnecessary to efficient learning. It is often only when the suspension of disbelief occurs that these students see the complexity and the value of the learning environment.

\section{What are authentic activities?}

The use of the word authentic is quite open to interpretation. Bennett, Harper and Hedberg (2001) have usefully discussed the multiple interpretations that abound in the literature, ranging from activities based 
on real situations to models that focus on applying conceptual knowledge or skills, such as critical thinking or problem solving. Several authors have attempted to delineate characteristics of authentic activities. For example, Young (1993) listed the attributes of real life problems which need, where possible, to be replicated in authentic activities, such as active/generative engagement in defining problems as well as solving them, and involvement of the student's beliefs and values. Jonassen (1991) defined authentic activities as tasks: that have real world relevance and utility, that integrate across the curriculum, that provide appropriate levels of complexity, and that allow students to select appropriate levels of difficulty or involvement. Similarly, Bransford, Vye, Kinzer and Risko (1990) described criteria of authentic activities such as: a single complex problem should be investigated by the students, students identify and define their own questions, and activities are logically related to the problem. The Cognition and Technology Group at Vanderbilt (1990) have stressed the importance of complexity and the necessity to provide an environment capable of sustained examination. They describe authentic tasks as 'generative' because the completion of the task requires the students to generate other problems to be solved. Kantor, Waddington and Osgood (2000) have a well-defined level of authenticity for their goal based scenarios, largely designed for business consulting training:

We make them authentic to the degree that the staging of theatrical productions is authentic. We provide physical props (plans, offices, desks) ...We locate furniture, phones, computer equipment, flip charts and white boards in the team rooms to promote the right mix of team collaboration and communication, creation of work products and research activities. These levels of authenticity are set to the degree that such models of communication require, but no more. (p. 222)

\section{0 characteristics of authentic activities}

Our own research has focussed on defining critical characteristics of authentic activities based on a wide literature review of recent research and theory. In reflecting on the characteristics of activities described by researchers, ten broad design characteristics of authentic activities have been identified (cf. Reeves, Herrington \& Oliver, 2002). These characteristics comprise:

- Authentic activities have real world relevance: Activities match as nearly as possible the real world tasks of professionals in practice rather than decontextualised or classroom based tasks.

- Authentic activities are ill-defined, requiring students to define the tasks and sub-tasks needed to complete the activity: Problems inherent in the activities are ill-defined and open to multiple interpretations rather than easily solved by the application of existing algorithms. Learners 
must identify their own unique tasks and sub-tasks in order to complete the major task.

- Authentic activities comprise complex tasks to be investigated by students over a sustained period of time: Activities are completed in days, weeks and months rather than minutes or hours. They require significant investment of time and intellectual resources.

- Authentic activities provide the opportunity for students to examine the task from different perspectives, using a variety of resources: The task affords learners the opportunity to examine the problem from a variety of theoretical and practical perspectives, rather than allowing a single perspective that learners must imitate to be successful. The use of a variety of resources rather than a limited number of preselected references requires students to detect relevant from irrelevant information.

- Authentic activities provide the opportunity to collaborate: Collaboration is integral to the task, both within the course and the real world, rather than achievable by an individual learner.

- Authentic activities provide the opportunity to reflect: Activities need to enable learners to make choices and reflect on their learning both individually and socially.

- Authentic activities can be integrated and applied across different subject areas and lead beyond domain specific outcomes: Activities encourage interdisciplinary perspectives and enable students to play diverse roles thus building robust expertise rather than knowledge limited to a single well-defined field or domain.

- Authentic activities are seamlessly integrated with assessment: Assessment of activities is seamlessly integrated with the major task in a manner that reflects real world assessment, rather than separate artificial assessment removed from the nature of the task.

- Authentic activities create polished products valuable in their own right rather than as preparation for something else: Activities culminate in the creation of a whole product rather than an exercise or sub-step in preparation for something else.

- Authentic activities allow competing solutions and diversity of outcome: Activities allow a range and diversity of outcomes open to multiple solutions of an original nature, rather than a single correct response obtained by the application of rules and procedures.

Using these characteristics as criteria for the selection of appropriate courses to study, our current research has sought to investigate the characteristics of authentic activity that facilitate a whole course or unit of 
study being encapsulated within complex tasks, and to determine the factors that contribute to the successful adoption and implementation of activity-based online courses or units. We have used the criteria listed above to select courses or units of study that use authentic activities as a central core of their presentation. Identification of courses that meet these criteria is difficult, and to date six cases have been investigated. The units must have a major online component, not simply supplementary material to on-campus delivery. Teachers, authors, instructional designers, tutors and others associated with the design and delivery of the courses have been interviewed, and the websites of courses have been analysed. The research is ongoing, and analysis is focusing on the identification of conceptual themes and issues emerging from the data, using techniques such as clustering, and making contrasts and comparisons (Miles \& Huberman, 1994).

One theme which has emerged strongly from a number of different sources in our research is the nature of authenticity, and how many authentic environments are the creation of the teachers', authors' and instructional designers' imaginations, and are thus inevitably someone's view of what is authentic. Petraglia (1998a) has been critical of this shortcoming, calling it 'the real world on a short leash' (p. 53). There is nevertheless, much evidence to suggest that these learning environments can provide a great deal of meaning to otherwise decontextualised facts and skills, and can enhance the transfer of deep and lifelong learning (Barab \& Landa, 1997). At what point do students become engaged, if ever, in these manufactured scenarios? Is there a pattern to their acceptance of the terms of the authenticity, and how important is the suspension of disbelief?

\section{Patterns of engagement}

In analysing the interview data from teachers' and tutors' perceptions of student engagement, there appear to be different approaches adopted by students, and several issues have emerged from our examination of this aspect of authentic tasks. The learning environments that have been examined to date typically build a scenario into which students are immersed, and include an authentic context where students are given a role, and a task to perform to solve a significant problem. Resources are available on the websites to assist with their investigations, and the students collaboratively produce a polished and realistic product, such as a research report for assessment. The courses examined have included subjects in research methods, business communication and coastal and marine biology. Two main patterns of engagement have emerged from our initial data that appear to merit further investigation. 


\title{
Willing acceptance and 'relief'
}

The phrase 'willing suspension of disbelief' was first used by the early 19th century poet Samuel Taylor Coleridge. The term has been applied to many instances of human response to the arts, as noted by Milburn (n.d.):

[Coleridge's] original turn of the phrase was in reference to the reader's response to poetry, but everyone immediately realized he had summarized most of the human experience of art generally ... Whether you' re talking about a Spielberg movie, a Stephen King novel, a twitch-em-up video game, a multi-decibel rave, or a simple TV sitcom, they all require the same thing of spectators / participants: a willing suspension of disbelief. (Para no. 6)

However, the idea is also highly apposite to education. Laurel (1993) likened the willing suspension of disbelief to engagement: 'Engagement is what happens when we are able to give ourselves over to a representational action, comfortably and unambiguously. It involves a kind of complicity' (p. 115). In initial contact with authentic learning environments as described here, many students willingly and instantly engage. For example, one incident was described in the interviews which labelled the students' response as 'relief':

\begin{abstract}
There was less fear. There's an anecdote I can share is that the very first time the unit ran, we gave students an option of coming in to campus to look at it ... I stood behind two mature aged women who had expressed to me before things started that they didn't want to do this unit, they hated the idea of it, they were terrified of it, they really disliked the fact that they had to do it and were quite negative about it. They were talked through how to access the site ... they turned to each other and [said] words to the effect of 'Oh wow, this is going to be great'. And they immediately weren't scared of it. There was a real sense of relief and I think that's because it was presented in a human form. (Interview with Camille)
\end{abstract}

Similarly, there was evidence of a willing acceptance of the characters and parameters of the scenarios developed using authentic tasks, described by Laurel (1993) as a willingness to think and feel in terms of both the content and conventions of a mimetic context' (p. 115). Students can readily become so immersed in the learning context that has been created for them that they begin to see the characters as real:

The most interesting part for me was when we piloted it and ... one day I walked in and the students were there in the lab ... chatting to each other, and they were going on and on about this person they were having trouble with, and I inquired about it and it turned out it was [one of the characters] and I said as gently as I could 'That's not a real person, it's a character' and they said 'We know that' and then they just ignored me and kept conversing with each other about what an awful person he was and how difficult they were finding him, as if he was real, and I found that interesting. (Interview with Brooke) 
It was also apparent in the interviews that the veracity of the learning environment and its physical representation on the website was not a critical factor for those students who engaged with the context from the outset. For example:

[We] very deliberately didn't try, to make ... total simulation out of it. There is so much suspension of disbelief required, but the point was, there just had to be enough to get them engaged.' (Interview with Carlo).

The quality of the graphics and images was not seen as important to students if they had accepted the basic context of the scenario:

If it were a commercial product, I'd be disappointed in some of the technology and the graphics that I think are low end. If we spent a bit more money on it we could have something that looked a lot more professional ... but I think that is a relatively trivial point at the moment. Yes, I think it's been engaging; I think the students have learnt at a higher level. (Interview with Camille)

Similarly, another teacher pointed out that the original design for the website planned to include realistic graphics and photographs as a faithful reproduction of a real-world work environment. Instead, the website was tested with simple sketches:

Our concern was that the sketches wouldn't seem as real to the students. When we piloted it, it worked sensationally. I suppose the students these days are so used to the blending of artificial and the real it didn't bother them at all. (Interview with Brooke)

This observation that many, particularly younger, students have little trouble adapting to the conventions and conduct of web-based scenarios may be a legacy of popular computer and strategy games that have successfully incorporated complex and sustained scenarios in their design. Nevertheless, these responses cannot be considered to be restricted to this age group, as many students across the board show immediate and sustained acceptance of authentic learning environments:

There is quite clear evidence that very large numbers of the students become deeply engaged. The evidence is overwhelming that the students mostly become very seriously committed to this scenario and they do find it deeply engaging. (Interview with Camille)

\section{Delayed engagement}

The capacity of authentic learning settings to promote students' willing suspension of disbelief is a powerful outcome and one that appears to hold strong prospects for enhancing the effectiveness of a range of learning settings that promote knowledge construction. Many students experience problems with learning environments that focus on learner- 
centred tasks and activities. For example, Taplin (2000) has noted that students may have difficulty in changing dependent learning habits, that problems can arise if students are not self-motivated and that many are accustomed to teacher-centred modes of instruction and are unhappy when this directed support is withdrawn. Others such as Hoffman and Ritchie (1997) have found that some students experience discomfort at 'the increased degree of freedom they experience' when they are accustomed to 'comprehension and synthesis of instructor-specified information, based on instructor-formulated learning objectives, and participation in instructor-led learning activities' (p. 100). Some students resist authentic approaches to such a degree that reports of angry emails and accusations of not being taught are not uncommon. For instance, Taplin (2000) reports from one of the teachers participating in her study: 'One participant found that there was very strong resistance-almost to the point of mutinyfrom one group of students because "they are too exam oriented. They didn't take it easily when accepting the new teaching mode" ' (p. 293). One respondent in our study described some student anger and frustration with the scenario, and the types of questions that were asked in video interviews:

They get really angry with 'dumb' questions and start being so particular about the video clips and the sorts of questions that they think need to be asked. (Interview with Violet)

Few teachers in our study described any sustained resistance to authentic approaches, although there were several comments about initial inability to accept the learning environment wholeheartedly. For example, one respondent likened the experience to the theatre-going experience:

\footnotetext{
There will be a period where they won't get engaged, but that's the same as going to a play I think. If the actors don't win you over then you don't enjoy it, and you don't mentally participate. So that very much puts the role of the tutor or mentor or lecturer in the forefront because they can either make or break the students' attitude to the task and simulation in terms of how they are presented to the students and how seriously they take the situation. (Interview with Carlo)
}

This respondent also pointed out that student resistance is not unexpected in environments where mistakes can happen, and where a great deal of material has to be worked through to find the critical knowledge that will assist with the problem:

I know one of the difficulties ... is that there is a lot of text that students may need to go through at the beginning before they actually begin doing stuff. And I think that's always a problem so that they will be a little bit disoriented because of the amount of material they're processing before they even get to the problem. (Interview with Carlo) 
Similarly, frustration can arise simply because of the similarity of these authentic learning tasks to the kind of uncertain and messy tasks that people are often required to do in their professional lives. One teacher pointed out that students need to be given the time and space to make these mistakes:

There's not very many complex things that you would ask people to do in the workplace that you would ask them to have in by tomorrow, and I think you've got to give them the same operating rules as somebody in the workplace would have. So generally I do think you have to give them time to make mistakes; to be inefficient in getting the information together and to increase their efficiency as they go on. (Interview with Blake)

In all the environments using authentic tasks examined to date in this study, even reluctant students were reported to have engaged within a few weeks of the semester. As stated by one teacher:

The data was real enough so that you would think it was real, and it becomes real. So within a couple of weeks they've shifted past the virtual and it's real! (Interview with Violet)

These findings provide support for the use of authentic environments for online learning settings. Our research suggests that the use of the authentic setting encourages and supports learners in their development of skills in self-regulation and self-learning, factors which have been seen to inhibit other forms of online learning. The capacity of the learning environment to encourage students' willing suspension of disbelief appears also to encourage self-direction and independent learningimportant success factors in online learning.

\section{Conclusion}

As educators move to adopt learning settings that focus on studentcentred rather than teacher-centred learning activities, the need for strategies to support and encourage learners in what are sometimes unfamiliar and discomforting activities becomes an important element in the design process. Support for students in the early weeks of immersion in student-centred learning environments is crucial. This is particularly important in online learning environments where isolation can be an additional mitigating factor against successful engagement with the course. Taplin (2000) has noted that acceptance of problem based learning scenarios, in addition to the usual difficulties in conventional situations, is exacerbated by distance because of the students' physical isolation.

Teacher support and peer scaffolding are often suggested as strategies that may assist students who are reluctant to engage with student-centred and problem-based tasks to persevere beyond the initial weeks of frustration 
and uncertainty. Our research suggests that the use of authentic learning settings can also provide strong supports for such learners. Authentic settings have the capability to motivate and encourage learner participation by facilitating students' willing suspension of disbelief. In this way, students become immersed in the setting and such immersion can provide the motivation that is needed for the initial perseverance. Once students have persevered with what can initially be quite discomforting and unfamiliar settings, they are able to develop the forms of familiarity and the skill sets required so that the authentic setting no longer provides a distraction from the cognitive engagement that higher order learning requires.

We would not agree with one of Taplin's respondents who contended that: 'As educators, we can't [just worry about pleasing] the students by not doing it at all. Rather we have to gradually brainwash them ... otherwise they will lose their competitiveness in this society' (p. 495). We believe, like O'Reilly (2000) that there is a need to humanise the online experience with greater compassion, empathy and open-mindedness. Authentic learning settings appear to be able to provide support in the initial stages of learning, enabling students to experience a suspension of disbelief, and through these means to be encouraged to persevere with their learning through initial difficulties. Our ongoing research seeks to explore the design principles that can accommodate and support these learning outcomes in online settings where the need for learner engagement is paramount to learning success.

\section{References}

Barab, S.A., \& Landa, A. (1997). Designing effective interdisciplinary anchors. Educational Leadership, 54, 52-55.

Barab, S.A., Squire, K.D., \& Dueber, W. (2000). A co-evolutionary model for supporting the emergence of authenticity. Educational Technology Research and Development, 48(2), 37-62.

Bennett, S., Harper, B., \& Hedberg, J. (2001). Designing real-life cases to support authentic design activities. In G. Kennedy, M. Keppell, C. McNaught, \& T. Petrovic (Eds.), Meeting at the Crossroads. Proceedings of the 18th Annual Conference of the Australian Society for Computers in Learning in Tertiary Education (pp. 73-81). Melbourne: Biomedical Multimedia Unit, University of Melbourne. http:/ / www.ascilite.org.au/ conferences/melbourne01/pdf/papers/bennetts.pdf

Bransford, J.D., Vye, N., Kinzer, C., \& Risko, V. (1990). Teaching thinking and content knowledge: Toward an integrated approach. In B.F. Jones \& L. Idol (Eds.), Dimensions of thinking and cognitive instruction (pp. 381-413). Hillsdale, NJ: Lawrence Erlbaum Associates. 
Bullen, F. \& Karri, V. (2002). Design and construction of a Formula SAE racecar in a teaching and research framework. In A. Goody, J. Herrington \& M. Northcote (Eds), Quality conversations: Research and Development in Higher Education, Volume 25 (pp. 74-82). Jamison, ACT: HERDSA. [verified 6 Feb 2003] http: / / www.ecu.edu.au/conferences/herdsa / papers/ref/pdf/Bullen.pdf

Challis, D. (2002). Integrating the conceptual and practice worlds: A case study from architecture. In A. Goody, J. Herrington \& M. Northcote (Eds), Quality conversations: Research and Development in Higher Education, Volume 25 (pp. 106113). Jamison, ACT: HERDSA. [verified 6 Feb 2003] http: / / www.ecu.edu.au/conferences/herdsa/papers/ ref/pdf/Challis.pdf

Cognition and Technology Group at Vanderbilt. (1990). Technology and the design of generative learning environments. Educational Technology, 31(5), 34-40.

Hoffman, B., \& Ritchie, D. (1997). Using multimedia to overcome the problems with problem based learning. Instructional Science, 25, 97-115.

Hunt, L., Kershaw, L., \& Seddon, J. (2002). Authentic transitions: The Click Around ECU online transition to university program. In A. Goody, J. Herrington \& M. Northcote (Eds), Quality conversations: Research and Development in Higher Education, Volume 25 (pp. 338-353). Jamison, ACT: HERDSA. [verified 6 Feb 2003] http:/ / www.ecu.edu.au/conferences/herdsa/ papers/ref/pdf/Hunt.pdf

Jonassen, D. (1991). Evaluating constructivistic learning. Educational Technology, 31(9), 28-33.

Kantor, R.J., Waddington, T., \& Osgood, R.E. (2000). Fostering the suspension of disbelief: The role of authenticity in goal-based scenarios. Interactive Learning Environments, 8(3), 211-227.

Laurel, B. (1993). Computers as theatre. Reading, MA: Addison-Wesley.

Miles, M.B., \& Huberman, A.M. (1994). Qualitative data analysis: An expanded sourcebook (2nd. ed.). Thousand Oaks, CA: Sage.

Marshall, L., Northcote, M., \& Lenoy, M. (2001). Design influences in the creation of an online mathematics unit for indigenous adults. In G. Kennedy, M. Keppell, C. McNaught, \& T. Petrovic (Eds.), Meeting at the Crossroads. Short Paper Proceedings of the 18th Annual Conference of the Australian Society for Computers in Learning in Tertiary Education (pp. 113-116). Melbourne: Biomedical Multimedia Unit, University of Melbourne. http:/ / www.ascilite.org.au/conferences/melbourne01/pdf/papers/marshalll.pdf

Milburn, D. (n.d.). Magellan's log: Culture, counterculture, anticulture: The willed suspension of disbelief. [viewed July 2002, verified 6 Feb 2003] http: / / www.texaschapbookpress.com/magellanslog8/ disbelief.htm

O'Reilly, M. (2000). Reinvigorating educational design for an online world. In R. Sims, M. O'Reilly , \& S. Sawkins (Eds.), Learning to choose: Choosing to Learn: Proceedings of the 17th Annual ASCILITE Conference (pp. 255-264). Lismore, NSW: Southern Cross University Press. http: / / www.ascilite.org.au / conferences / coffs00 / papers / meg_oreilly.pdf 
Petraglia, J. (1998a). The real world on a short leash: The (mis)application of constructivism to the design of educational technology. Educational Technology Research and Development, 46(3), 53-65.

Petraglia, J. (1998b). Reality by design: The rhetoric and technology of authenticity in education. Mahwah, NJ: Lawrence Erlbaum Associates.

Reeves, T.C., Herrington, J., \& Oliver, R. (2002). Authentic activities and online learning. In A. Goody, J. Herrington, \& M. Northcote (Eds.), Quality conversations: Research and Development in Higher Education, Volume 25 (pp. 562567). Jamison, ACT: HERDSA. [verified 6 Feb 2003]

http: / / www.ecu.edu.au/conferences/herdsa/papers/ref/pdf/Reeves.pdf

Rice, M., Owies, D., Campbell, A., Snow, R., Owen, N., \& Holt, D. (1999). V-Lab: A virtual laboratory for teaching introductory concepts and methods of physical fitness and function. Australian Journal of Educational Technology, 15(2), 188-206. http: / / www.ascilite.org.au/ajet/ajet15/ rice.html

Taplin, M. (2000). Problem-based learning in distance education: Practitioners' beliefs about an action learning project. Distance Education, 21(2), 284-307.

Young, M.F. (1993). Instructional design for situated learning. Educational Technology Research and Development, 41(1), 43-58.

\section{Acknowledgements}

This research is supported by the Australian Research Council and the Australian-American Fulbright Commission.

This article was nominated for an Outstanding Paper Award at ASCILITE 2002, gaining the additional recognition of publication in AJET (with minor revisions). The reference for the Conference version is:

Herrington, J., Oliver, R. and Reeves, T. C. (2002). Patterns of engagement in authentic online learning environments. In A. Williamson, C. Gunn, A. Young and T. Clear (Eds), Winds of Change in the Sea of Learning: Proceedings of the 19th Annual Conference of the Australasian Society for Computers in Learning in Tertiary Education, pp279-286. Auckland, New Zealand: UNITEC Institute of Technology.

Jan Herrington, School of Communications and Multimedia, Edith Cowan University, Australia. j.herrington@ecu.edu.au

Ron Oliver, School of Communications and Multimedia, Edith Cowan University, Australia.r.oliver@ecu.edu.au

Thomas C. Reeves, College of Education, The University of Georgia, Georgia, USA. treeves@coe.uga.edu 